\title{
DESENVOLVIMENTO PROFISSIONAL DOCENTE NA PERSPECTIVA DA \\ PARTICIPAÇÃO SINDICAL: DIÁLOGOS PROPOSITIVOS PARA QUALIFICAÇÃO DO PLANO DE CARREIRA DOS PROFESSORES MUNICIPAIS DE SANTA MARIA - RS
}

\author{
DESARROLLO PROFESIONAL DOCENTE DESDE LA PERSPECTIVA DE LA \\ PARTICIPACIÓN SINDICAL: DIÁLOGOS PROPOSITIVOS PARA LA CALIFICACIÓN \\ DEL PLAN DE CARRERA DE LOS PROFESORES MUNICIPALES DE SANTA \\ MARÍA/RS
}

TEACHER PROFESSIONAL DEVELOPMENT FROM THE PERSPECTIVE OF UNION PARTICIPATION: PROPOSITIONAL DIALOGUES FOR THE QUALIFICATION OF THE CAREER PLAN OF MUNICIPAL TEACHERS OF SANTA MARIA/RS

RESUMO: Este trabalho tem por objetivo contribuir para o desenvolvimento profissional docente com vistas a qualificar a hora atividade, bem como evidenciar o protagonismo do sindicato nesse processo. Teve como objetivo compreender de que forma o Plano de Carreira do Magistério da Rede Municipal de Educação de Santa Maria - RS, a partir do direito a hora atividade pode contribuir no desenvolvimento profissional docente, bem como o sindicato pode se constituir protagonista nesse processo. A abordagem metodológica esteve baseada na Pesquisa Colaborativa (IBIAPINA, 2018) com construção dos dados a partir dos Círculos Dialógicos (HENZ,2015) e a compreensão e interpretação na perspectiva da Hermenêutica de (GADAMER,1999), bem como recorremos à análise documental. A pesquisa evidenciou a necessidade do cumprimento da Lei 11.738/08 que, além de um piso salarial básico, determina $1 / 3$ da carga horária do professor destinada para atividades de planejamento de atividades e formação, preferencialmente, no contexto das escolas e transformar a escola e a sala de aula em ambiente de pesquisa e reflexão sobre a prática. Portanto, a defesa dos Planos de Carreira enquanto instrumento referencial para a luta dos docentes na efetivação da valorização profissional e garantia de direitos culminou construção de uma proposta para a Secretaria de Município da Educação a com estratégias para o Desenvolvimento Profissional Docente.

PALAVRAS-CHAVE: Desenvolvimento profissional docente. Plano de carreira. Sindicato. Valorização profissional.

${ }^{1}$ Universidade Federal de Santa Maria (UFSM), Santa Maria - RS - Brasil. PPG Mestrado Profissional em Políticas Públicas e Gestão Educacional. OrcID: https://orcid.org/0000-0002-7778-4195. E-mail: marthanajar64@gmail.com.

${ }^{2}$ Universidade Federal de Santa Maria (UFSM), Santa Maria - RS - Brasil. Professor Titular da Universidade Federal de Santa Maria. OrcID: https://orcid.org/0000-0002-3982-7297. E-mail: elisiane.lunardi@gmail.com 
RESUMEN: Este trabajo tiene como objetivo contribuir al desarrollo profesional de los docentes con el fin de calificar el tiempo de actividad, así como destacar el protagonismo del sindicato en este proceso. El objetivo de entender cómo el Plan de Carrera del Magisterio de la Red Municipal de Educación de Santa María/RS, desde el derecho a la actividad de la hora puede contribuir al desarrollo profesional de los profesores, así como el sindicato puede ser protagonista en este proceso. El enfoque metodológico se basó en la Investigación Colaborativa (IBIAPINA, 2018) con la construcción de datos de Círculos Dialogicales (HENZ,2015) y la comprensión e interpretación desde la perspectiva de hermenéutica (GADAMER,1999), así como el uso del análisis documental. La investigación mostró la necesidad de cumplir con la Ley 11.738/08, que, además de un piso de salario básico, determina 1/3 de la carga de trabajo del profesor para la planificación y formación de actividades, preferentemente en el contexto de las escuelas y transformando la escuela y el aula en un entorno de investigación y reflexión sobre la práctica. Por lo tanto, la defensa de los planes de carrera como instrumento de referencia para la lucha de los maestros en la realización del aprecio profesional y la garantía de derechos culminó con la construcción de una propuesta para el Departamento de Municipio de Educación con estrategias para el Desarrollo Profesional del Profesorado.

PALABRAS CLAVE: Desarrollo profesional del professorado. Plan de carrera. Unión Europea. Agradecimiento profesional.

ABSTRACT: This work aims to contribute to the professional development of teachers with a view to qualifying the activity time, as well as to highlight the protagonism of the union in this process. The objective of understanding how the Career Plan of the Magisterium of the Municipal Education Network of Santa Marial RS, from the right to hour activity can contribute to the professional development of teachers, as well as the union can be a protagonist in this process. The methodological approach was based on Collaborative Research (IBIAPINA, 2018) with data construction from Dialogical Circles (HENZ,2015) and understanding and interpretation from the perspective of Hermeneutics (GADAMER,1999), as well as using documentary analysis. The research showed the need to comply with Law 11,738/08, which, in addition to a basic salary floor, determines 1/3 of the teacher's workload for activities planning and training, preferably in the context of schools and transforming the school and classroom into a research and reflection environment on practice. Therefore, the defense of career plans as a reference instrument for the struggle of teachers in the realization of professional appreciation and guarantee of rights culminated in the construction of a proposal for the Department of Municipality of Education to with strategies for Teacher Professional Development.

KEYWORDS: Teacher professional development. Career plan. Union. Professional appreciation. 


\section{Introdução}

A importância do desenvolvimento da profissionalidade docente ${ }^{3}$ coloca aos sindicatos de professores uma atribuição fundamental na medida que pressupõe a inseparabilidade entre formação e os temas que historicamente permearam o campo da atuação sindical. Assim, (ALMEIDA, 2000) salienta que o sindicato precisa se relacionar com os professores de modo que restabeleçam os vínculos que os identificam como coletivo profissional, sendo articuladores de movimentos de defesa de interesses específicos de suas categorias como salário, jornada de trabalho, plano de carreira entre outros.

Nesse cenário, este estudo é resultado de pesquisa desenvolvida no âmbito Mestrado Profissional em Políticas Públicas e Gestão Educacional do Programa de Pós-Graduação em Políticas Públicas e Gestão Educacional, Linha de Pesquisa Políticas e Gestão da Educação Básica da Universidade Federal de Santa Maria - RS.

Buscamos responder a seguinte problemática: Como o Plano de Carreira dos professores municipais de Santa Maria - RS contribui para o desenvolvimento profissional no âmbito da formação permanente de professores a partir da participação sindical? Tem por objetivo contribuir para o desenvolvimento profissional no âmbito da formação permanente de professores a partir da participação sindical em consonância com o Plano de Carreira do Magistério da Rede Municipal de Educação de Santa Maria - RS, Lei no 4696/03.

\section{Desenvolvimento profissional docente na perspectiva da participação sindical}

A formação permanente decorre de uma concepção de Desenvolvimento Profissional que deve considerar os sistemas e redes de ensino, o projeto pedagógico das escolas e o contexto onde está inserida, acompanhar a inovação e o desenvolvimento associados ao conhecimento, à ciência e à tecnologia, respeitar o protagonismo do professor e oferecer um espaço-tempo que lhe permita refletir criticamente e aperfeiçoar sua prática, o diálogo e a parceria com atores e instituições competentes, capazes de contribuir para alavancar novos patamares de qualidade ao complexo trabalho de gestão da sala de aula e da instituição educativa.

${ }^{3} \mathrm{~A}$ profissionalidade docente está diz respeito ao conhecimento profissional específico; a maneira de ser e atuar como docente; a construção de uma identidade profissional baseada nas ações do professor a partir de aspectos internos e externos à escola, o desenvolvimento de habilidades próprias do ato de ensinar fundamentado na formação inicial e continuada bem como, das experiências no decorrer do ofício de professor. 
O desenvolvimento profissional remete a ideia de processo, aprender é contínuo e essencial e está concentrado em dois pilares, a pessoa como agente e a escola como lugar de crescimento profissional permanente (NÓVOA, 1995), sugerindo uma ligação entre as dimensões pessoal e profissional na produção identitária do professor com um forte sentido cultural, numa profissionalidade docente que não pode deixar de se construir no interior de uma pessoalidade de professor (NÓVOA, 2009). Dois aspectos se colocam centrais nessa construção, o professor precisa ser detentor de um saber específico, que é fundamental para sua atuação, o qual é desenvolvido no interior de sua profissão e o trabalho docente precisa ser concebido e desenvolvido de maneira coletiva. (ALMEIDA, 2000).

Nesse espectro, o trabalho docente no decorrer dos tempos tornou-se mais complexo e diversificado, a transmissão de conhecimentos já não se sustenta, são necessárias outras funções que requerem uma nova formação, seja no âmbito da formação inicial ou na continuada (IMBERNÓN, 2011). Nessa perspectiva (GARCIA, 1999, p. 137) diz que "[...] o conceito de desenvolvimento tem uma conotação de evolução e continuidade que nos parece superar a justaposição entre formação inicial e aperfeiçoamento de professores”. Assim, a formação ultrapassa a simples atualização científica, pedagógica e didática e passa a conceber outros espaços, como os de participação, reflexão e formação para que as pessoas aprendam e se adaptem para poder conviver com a mudança e a incerteza (IMBERNÓN, 2011), promovendo o desenvolvimento de paradigmas que favoreçam a formação de professores reflexivos capazes de assumir a responsabilidade de seu próprio desenvolvimento profissional.

\section{Auto(trans)formação permanente, diálogo reflexivo com professores}

Rompendo com o paradigma da racionalidade, que orientado pelo positivismo declarava a supremacia da razão para compreender e explicar os fatos (CHIZZOTTI, 2006), optou-se por uma pesquisa de abordagem qualitativa, pois compreende o processo como um todo. É uma pesquisa do tipo colaborativa em educação com formação de professores. Essa dupla dimensão privilegia pesquisa e formação, fazendo avançar os conhecimentos produzidos na academia e na escola (IBIAPINA, 2008, p.07). Além disso, o desenvolvimento de um trabalho colaborativo presume a criação de relações que compreendem interesses pessoais e sociais comuns entre os participantes da pesquisa. 
Os constructos da pesquisa se deram por meio dos Círculos Dialógicos InvestigativoFormativos ${ }^{4}$, baseado nos Círculos de Cultura ${ }^{5}$. Rodas onde "[...] as gentes da comunidade se juntaram em uma ação dialógica, em um trabalho coletivo, coparticipado, lugar de compartilhar conhecimento, realidades, experiências e esperanças[...]” (HENZ; FREITAS; SILVEIRA, 2018, p. 839) porque os sujeitos aprendem em reciprocidade de consciência, pois não existem sábios ou ignorantes absolutos, mas homens que em comunhão buscam saber mais (FREIRE, 1987).

Configura-se como uma proposta político-epistemológica caracterizada por movimentos que não ocorrem de forma linear ou estanque, mas imbricados uns nos outros numa espiral ascendente proativa composta por escuta sensível e olhar aguçado; descoberta do inacabamento; emersão/imersão nas temáticas; diálogos problematizadores; distanciamento/desvelamento da realidade; registro re-criativo; conscientização e auto(trans)formação (HENZ, 2015). Também, abarca os construtos da Hermenêutica, ciência cuja interpretação e compreensão dos problemas leva em consideração a nossa compreensão, nossos pré-conceitos, mas dispostos a rever-nos em diálogo com ele, possui força transformadora.

A figura a seguir evidencia a Hermenêutica e sua contribuição na formação de professores enquanto experiência de relações humanas, a qual indica o movimento constituído nesse estudo.

\footnotetext{
${ }^{4} \mathrm{~A}$ metodologia dos Círculos Dialógicos Investigativo-formativos é desenvolvida pelo Grupo de Pesquisa Dialogus: Educação, Formação e Humanização com Paulo Freire da Universidade Federal de Santa Maria, RS

${ }^{5}$ Sistematizados por Paulo Freire fundamentam-se como uma proposta pedagógica de caráter democrático e libertador que rompe com a ideia de educação bancária e o modelo tradicional de ensino, valorizando a cultura, o saber prévio e apalavra do educando.
} 
Figura 1- Círculo Hermenêutico da Pesquisa

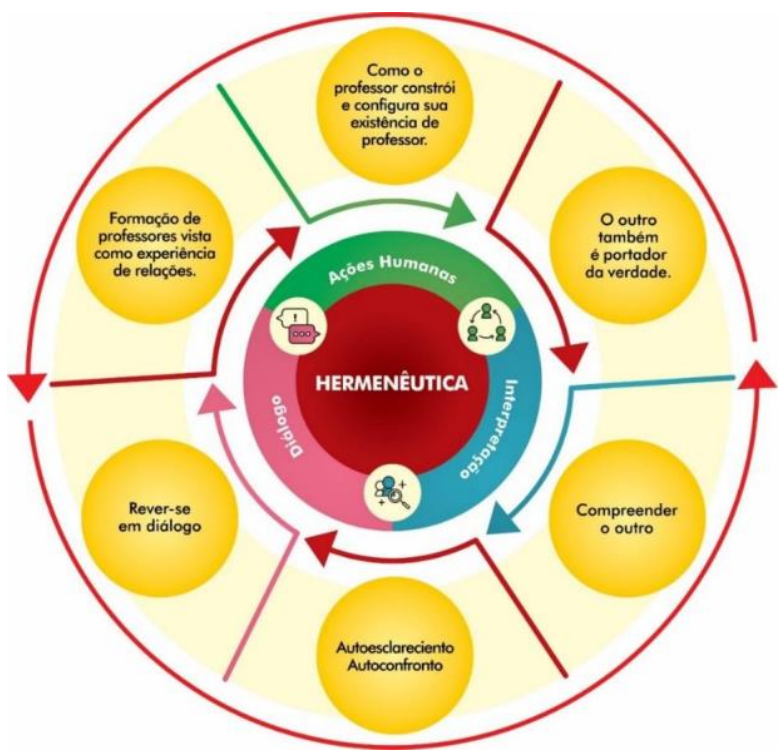

Fonte: as autoras (2019).

Como representação do movimento dialógico a Hermenêutica, é uma ciência que trata de problemas quando se está lidando com ações humanas dotadas de significados e com produtos dessa ação. Gadamer (1999) a Hermenêutica leva a saber o quanto fica de não-dito quando se diz algo. Assim, ao realizarmos a interpretação de um texto colocamos nele nossa compreensão, nossos pré-conceitos, mas dispostos a rever-nos em diálogo com ele. Nesse sentido, não há a última palavra, mas a possibilidade de estarmos abertos para o diálogo.

Para Rosek (2012), a Hermenêutica requer abertura e reconhecimento do outro como alguém capaz de ser portador da verdade. Nesta perspectiva, o caminho hermenêutico é a possibilidade de autoesclarecimento, de auto-confronto, pois se trata de um processo de interpretação da própria experiência como um ato de construção de sentidos sobre si (ROSEK, 2012). Portanto, pensar a formação do professor nesta ótica é buscar afirmar um sentido especial ao conceito de formação, pois é fundamental compreender como o sujeito professor constrói e configura sua existência como professor.

Apontamos, também, que pesquisa documental se faz necessário no sentido de ampliar o entendimento de determinadas questões a partir de uma contextualização dos aspectos da legislação a respeito do tema estudado considerando a Lei Municipal no 4696/03 que estabelece o Plano de Carreira do Magistério de Santa Maria - RS, especificamente com respeito ao art. 22 que garante tempo reservado na carga horária do professor para atividades de planejamento, avaliação, reuniões pedagógicas e formação. 
Portanto, foram realizados 05 (cinco) Círculos Dialógicos na sede do Sindicato dos Professores Municipais entre os meses de abril e julho de 2019. Participaram da pesquisa 08(oito) professoras, que de acordo com os pressupostos da proposta político-metodológica dos Círculos Dialógicos são reconhecidas como coautoras e fazem parte da Coordenação do Sindicato dos professores Municipais de Santa Maria - SINPROSM. Os encontros foram gravados e transcritos mediante prévia autorização dos professores. No primeiro encontro as coautoras foram convidadas a escolher um nome pelo qual seriam identificadas na pesquisa. A escolha foi de acordo com as expectativas em relação aos Círculos Dialógicos, processos vividos na docência ou por escolhas pessoais de vida.

A figura a seguir, representa o caminho metodológico construído pelas coautoras e pesquisadora. Nos encontros dos Círculos Dialógicos alguns movimentos foram importantes para desencadear o diálogo, a escuta sensível e o olhar aguçado, a emersão e imersão nas temáticas através de diálogos problematizadores e o distanciamento da realidade que proporcionam a conscientização e descoberta do inacabamento mobilizando-se em direção a auto(trans)formação. Todo esse movimento foi capaz de mobilizar os sujeitos coautores em direção ao pressuposto de um trabalho que resulta na ação-reflexão-ação enquanto possibilidade de prática docente em que o professor deixa de ser simplesmente objeto de investigação, tornando-se sujeito dela.

Figura 2 - Caminho Metodológico

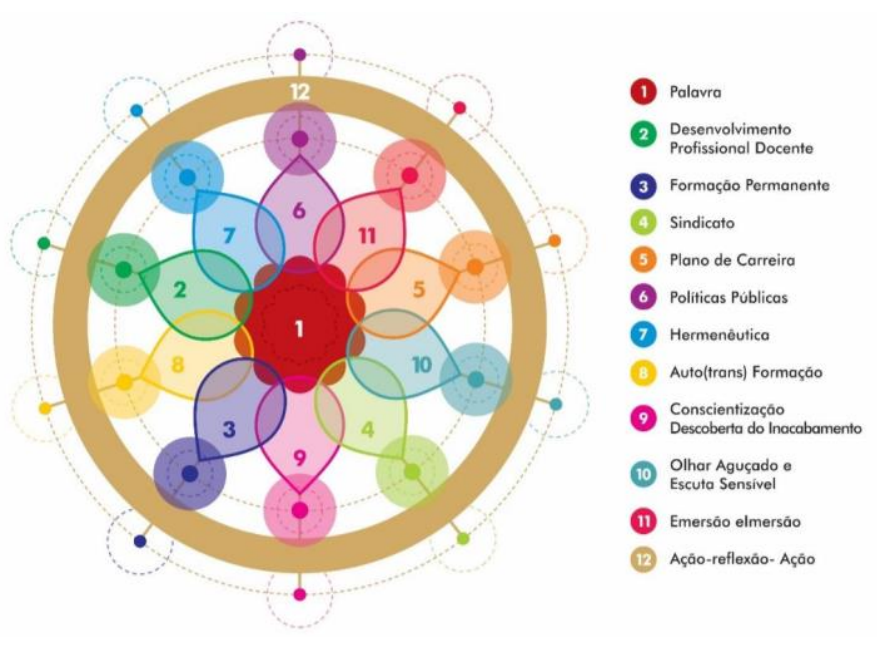

Fonte: as autoras (2019)

Considerando o respeito à palavra, através da manifestação das coautoras, junto com o sindicato, procurou-se analisar o Plano de Carreira dos Professores à luz das Políticas 
Públicas para tratar do Desenvolvimento Profissional Docente sob a ótica da formação permanente.

Entende-se que professor motivado para desenvolver trabalho com qualidade requer, entre outras coisas, que sua opinião seja respeitada nas decisões que se tomam na escola e na gestão do sistema de ensino. Também, um professor não pode dedicar-se de forma absoluta ao seu trabalho se recebe salários não condizentes com a sua função e em condições de trabalho profundamente deficitárias com salas superlotadas, escolas com estruturas físicas insatisfatórias e pesadas jornadas de trabalho e o exercício docente diário em escolas distantes entre si exigindo ainda um esforço maior para o seu deslocamento para cumprir as suas atribuições com competência e responsabilidade.

A valorização dos profissionais da educação se dá com programas de formação permanente, remuneração compatível com a jornada de trabalho definida no projeto políticopedagógico enquanto condições para uma escola com qualidade social.

Para corresponder à importância deste papel social, o trabalho do professor precisa ser valorizado. É nesta perspectiva que devemos considerar a importância da Lei do Piso Salarial Profissional Nacional, Lei $\mathrm{n}^{\circ} 11.738 / 08$, tanto em termos salariais quanto em relação às condições de trabalho efetivadas na composição da jornada de trabalho que esta lei determina e que dá possibilidades de proporcionar a formação permanente de professores.

\section{Diálogos auto(trans)formativos, círculos dialógicos com as coautoras}

A respeito do papel do sindicato enquanto desencadeador do desenvolvimento profissional, destaca-se as falas da coautora que ressalta o papel do sindicato como elemento aglutinador cuja incumbência pode ultrapassar os limites da defesa de direitos e se propor a discutir o assunto na perspectiva de que buscar formação também é um movimento de luta e resistência.

A narrativa da coautora Bibiana lembra que na visão de algumas pessoas o sindicato tem um papel que se resume à resolução de problemas particulares dos associados, minimizando o papel do sindicato em relação às causas coletivas.

Para algumas pessoas o sindicato serve apenas para resolver os seus problemas, aquela suplementação que faltou, a gratificação que não veio. (BIBIANA, Círculos Dialógicos, 2019).

Entretanto, é possível afirmar que existe um vasto campo de possibilidades de atuação para o sindicato no contexto do desenvolvimento profissional docente. Conjuntamente com a 
escola, ele também é espaço de construção do sujeito coletivo, e ao mesmo tempo de sua manifestação (ALMEIDA, 2000). Para a mesma autora o sindicato precisa se relacionar com os professores de modo que estabeleçam os vínculos que os identificam como coletivo profissional.

Partindo do princípio, que desenvolvimento profissional abrange também, a compreensão da construção da profissionalidade inserida dentro de um contexto para além da sala de aula, considerando a sua carreira docente incluindo jornada de trabalho, salário, condições de trabalho, relações de poder é mister tratar do assunto junto com o sindicato na esfera do enfrentamento enquanto lutas da categoria e para tanto é fundamental investigar profundamente essas questões junto aos seus associados. Conscientizar-se é movimento de desacomodação, de descobrir-se dando possibilidades de comportamento transformador de sentidos e ações a partir da reflexão das concepções de mundo.

Também é importante ressaltar que em tempos de desgaste das relações sindicais com as suas bases, bem como aos olhos da sociedade, em decorrência da conjuntura que vive o país se faz necessário restabelecer esse vínculo e uma das possibilidades é promover o desenvolvimento profissional docente aliado a defesa do Plano de Carreira da categoria, Lei Municipal $n^{\circ} 4.396 / 03$ que é um importante instrumento de valorização profissional, a formação permanente enquanto caminho de resistência em tempos que a educação e os educadores são tidos como inimigos da nação.

Contudo, a coautora Revoltada ouvindo as afirmações sobre o professor se reconhecer ou não trabalhador, faz uma análise da percepção de si enquanto professora.

Eu não tinha pensado dessa forma, mas eu sempre digo que amanhã é dia de trabalho, tem que ir. Eu falo mais em ir trabalhar do que ir dar aula. (REVOLTADA, Círculos Dialógicos, 2019).

Percebe-se na palavra manifestada das coautoras uma complexidade, por vez difícil de controlar, porque não depende só dos professores, mas das relações com os outros e com o contexto político e social. A ideia de luta, em tempos difíceis em razão da historicidade vivida e dinamicidade da realidade, exige que se compreenda a necessidade de se defrontar e saber, que apesar de condicionados, não somos determinados.

Logo, partindo das falas das coautoras, constata-se que o sindicato é impulsionador de possibilidades para o desenvolvimento profissional e que a hora atividade garantida no Plano de Carreira do magistério de Santa Maria - RS é de fato o espaço para formação permanente, no contexto da escola, enquanto possibilidade de articulação entre a formação e os projetos 
das escolas na perspectiva da construção de uma identidade profissional de forma individual e coletiva.

Assim, agir de forma reflexiva e coletiva acerca do Plano de Carreira é fator de afirmação profissional e o professor, através da participação com o seu sindicato, se apropria definitivamente do seu plano. Os processos formativos da profissão docente acontecem de forma individual e coletiva e deve haver tempos para formação dentro da sua carga horária de trabalho garantido no seu Plano de Carreira.

\section{A lei do piso do magistério e o plano de carreira dos professores municipais de Santa Maria - RS como princípio de valorização profissional}

O SINPROSM foi fundado em 15 de setembro de 1989 a partir do desmembramento do Sindicato dos Municipários do qual faziam parte os professores junto a todos ou outros servidores municipais. Atualmente conta com aproximadamente 1800 filiados entre ativos e aposentados. Enquanto sindicato docente é articulador de movimentos na defesa dos interesses específicos da categoria como plano de carreira, salário, jornada e condições de trabalho. Entretanto, também enfrenta o desafio da busca da melhoria da qualidade da educação, a manutenção e a defesa das instituições democráticas, a justiça social e as liberdades individuais e coletivas, além dos direitos fundamentais de mulheres e homens.

Para tratar dos aspectos específicos categoria, a proposta desta pesquisa foi reunir os coordenadores do SINPROSM em Círculos Dialógicos e promover a discussão sobre a necessidade de estudar o Plano de Carreira dos Professores Municipais de Santa Maria, Lei ${ }^{\circ}$ 4696/03, especialmente o artigo 22 que garante espaço para hora-atividade entendidas com as reservadas para estudo, planejamento e avaliação do trabalho didático e reuniões pedagógicas.

O Piso Salarial Nacional Profissional, (Lei $\left.\mathrm{n}^{\mathrm{o}} 11.738 / 08\right)^{6}$ é decorrência de um conjunto de leis desde a Constituição Federal de $1988^{7}$ que assegura no art. 206, entre outros, piso salarial profissional nacional para os profissionais da educação escolar pública (BRASIL, 1988). Mais tarde reafirmado na Lei de Diretrizes e Bases da Educação, (LDB/96, Lei no 9394/96) ${ }^{8}$ (BRASIL, 1996).

${ }^{6}$ Lei $\mathrm{n}^{\mathrm{o}}$ 11.738. De 16 de julho 2008. Regulamenta a alínea "e" do inciso III do caput do art. 60 do Ato das Disposições Constitucionais Transitórias, para instituir o piso salarial profissional nacional para os profissionais do magistério público da educação básica.

${ }^{7}$ Constituição da República Federativa do Brasil de 1988.

${ }^{8}$ Estabelece as diretrizes e bases da educação nacional. 
Nesse contexto, também foram criados, inicialmente, o Fundo de Manutenção e Desenvolvimento do Ensino Fundamental e de Valorização do Magistério ${ }^{9}$ FUNDEF, substituído pelo, Fundo de Manutenção e Desenvolvimento da Educação Básica e de Valorização do Magistério ${ }^{10}$ FUNDEB que garante no art. 22 remuneração dos profissionais de tal forma que, no mínimo, $60 \%$ (sessenta por cento) dos recursos anuais totais dos serão destinados ao pagamento da remuneração dos profissionais do magistério da educação básica (BRASIL, 1996, 2007).

Da análise deste arcabouço da legislação, a valorização do profissional da educação é apontada como fundamental para o desenvolvimento da educação no país assentada na convicção de que o cerne do processo educativo é o Projeto Político-Pedagógico de cada escola e centra o professor como ator principal deste processo. Como determina o artigo $13 \mathrm{da}$ LDB/96 os professores devem participar integralmente dos períodos dedicados ao planejamento, à avaliação e ao desenvolvimento profissional (BRASIL, 1996).

Ainda, o Parecer CNE/CEB $n^{\circ} 18 / 12^{11}$ ao analisar as especificidades do trabalho educativo argumenta que os professores das redes públicas vendem sua força de trabalho para o Estado, mesmo não estando diretamente vinculado à valorização do capital, não representa um investimento capitalista na produção de mercadorias e, portanto, não produz mais-valia ${ }^{12}$. Entretanto, seu trabalho é afetado pela forma como está organizado o sistema capitalista, uma vez que a organização e a gestão do processo educativo nas escolas, estão permeados pelos métodos gerenciais do sistema capitalista, na qual os trabalhadores são organizados por funções repetitivas e sequenciais, sem que qualquer um deles domine todo o processo produtivo (MEC, 2012). A esse respeito, a couatora Marina faz uma importante reflexão:

Nos veem como tarefeiros e não autores da prática. É movida (escola) pela lógica da produtividade, e entende isso numa perspectiva Fordista, de fábrica. (MARINA, Círculos Dialógicos, 2019).

${ }^{9}$ Lei n ${ }^{\circ}$ 9.424, de 24/12/96 - Dispõe sobre o Fundo de Manutenção e Desenvolvimento do Ensino Fundamental e Valorização do Magistério.

${ }^{10}$ Decreto ${ }^{\circ} 6253$ de 13 de novembro de 2007. Dispõe sobre o Fundo de Manutenção e Desenvolvimento da Educação Básica e de Valorização dos Profissionais da Educação - FUNDEB, regulamenta a Lei no 11.494, de 20 de junho de 2007, e dá outras providências.

${ }^{11}$ Conselho Nacional de Educação/Câmara de Educação Básica. Reexame do Parecer CNE/CEB nº 9/2012, que trata da implantação da Lei $\mathrm{n}^{\circ} 11.738 / 2008$, que institui o piso salarial profissional nacional para os profissionais do magistério público da Educação Básica

${ }^{12}$ Quando o sistema capitalista compra a força de trabalho do trabalhador, o faz por um determinado período de tempo, que configura a jornada diária de trabalho. Porém, o tempo necessário para que este trabalhador produza a quantidade de mercadorias que corresponde, em valores de mercado, ao suficiente para sua subsistência e de sua família, não esgota toda a jornada de trabalho contratada pelo empregador. Ele continua trabalhando e produzindo até o final de sua jornada. Este excedente de trabalho gera mercadorias, que contém, em si, uma determinada quantidade de valor. A este valor a mais, que é apropriado pelo capitalista, Marx chamou de "maisvalia". 
Embora muito se evidencie o trabalho coletivo, a tendência é de se reproduzir o modelo em o que professor é considerado como uma das peças do processo de modo que ele não pode inserir-se plenamente no processo, participando da definição das políticas, com condições de tempo, espaço e estrutura para interagir com seus pares. Destaca-se a narrativa de Persistência sobre a necessidade de uma escola que favoreça o diálogo, a reflexão e formação no coletivo:

Escola como espaço para trocas e enriquecimento e também como crescimento pessoal e profissional. Disponibilidade de tempo para ler e pensar sobre suas ações no dia a dia da escola e sua profissão com um todo. Enquanto tivermos esse papel de receptores de formação não haverá evolução, precisamos falar e ser ouvidos. (PERSISTẾNCIA, Círculos Dialógicos, 2019).

De acordo com a narrativa, dessa forma é possível apropriar-se de seu próprio trabalho e realizar integralmente sua função social, que não é apenas a de transmitir o saber historicamente acumulado, mas, também produzir novos conhecimentos e formar sujeitos conscientes, capazes de atuar de forma plena na sociedade (MEC, 2012).

Os espaços de trabalho pedagógico e outros espaços coletivos de interação do professor com seus pares e com os demais segmentos da comunidade escolar são fundamentais e devem ser contemplados em sua jornada de trabalho. São atividades intrínsecas à sua função como profissional da educação, tanto que ao fixar um valor para o trabalho do professor a Lei $n^{\circ} 11.738 / 08$, também determinou que na composição da jornada de trabalho, observar-se-á o limite máximo de $2 / 3$ (dois terços) da carga horária para o desempenho das atividades de interação com os educandos.

\section{Formação permanente enquanto elemento constituinte de desenvovimento profissional - professores reflexivos numa escola em constante transformação}

A partir dos movimentos realizados nos círculos dialógicos, na perspectiva de qualificação do espaço-tempo reservado no Plano de Carreira dos professores municipais de Santa Maria - RS, Lei Municipal n 4.696/03, especificamente o artigo 22 que garante, no mínimo, 20\% da carga horária para estudos, planejamento e avaliação do trabalho didático, apoiado na Lei $n^{\circ} 11.738 / 08$ que assegura no artigo $2^{\circ}, \S 4^{\circ}$ que na composição da jornada de trabalho, observar-se-á o limite máximo de 2/3 (dois terços) da carga horária para o 
desempenho das atividades de interação com os educandos na perspectiva de promover a formação permanente dos professores.

A figura a seguir é uma síntese dos resultados das discussões nos Círculos Dialógicos realizados durante os meses de abril a julho de 2019 com os professores coordenadores do SINPROSM e que também atuam nas escolas municipais de Santa Maria - RS.

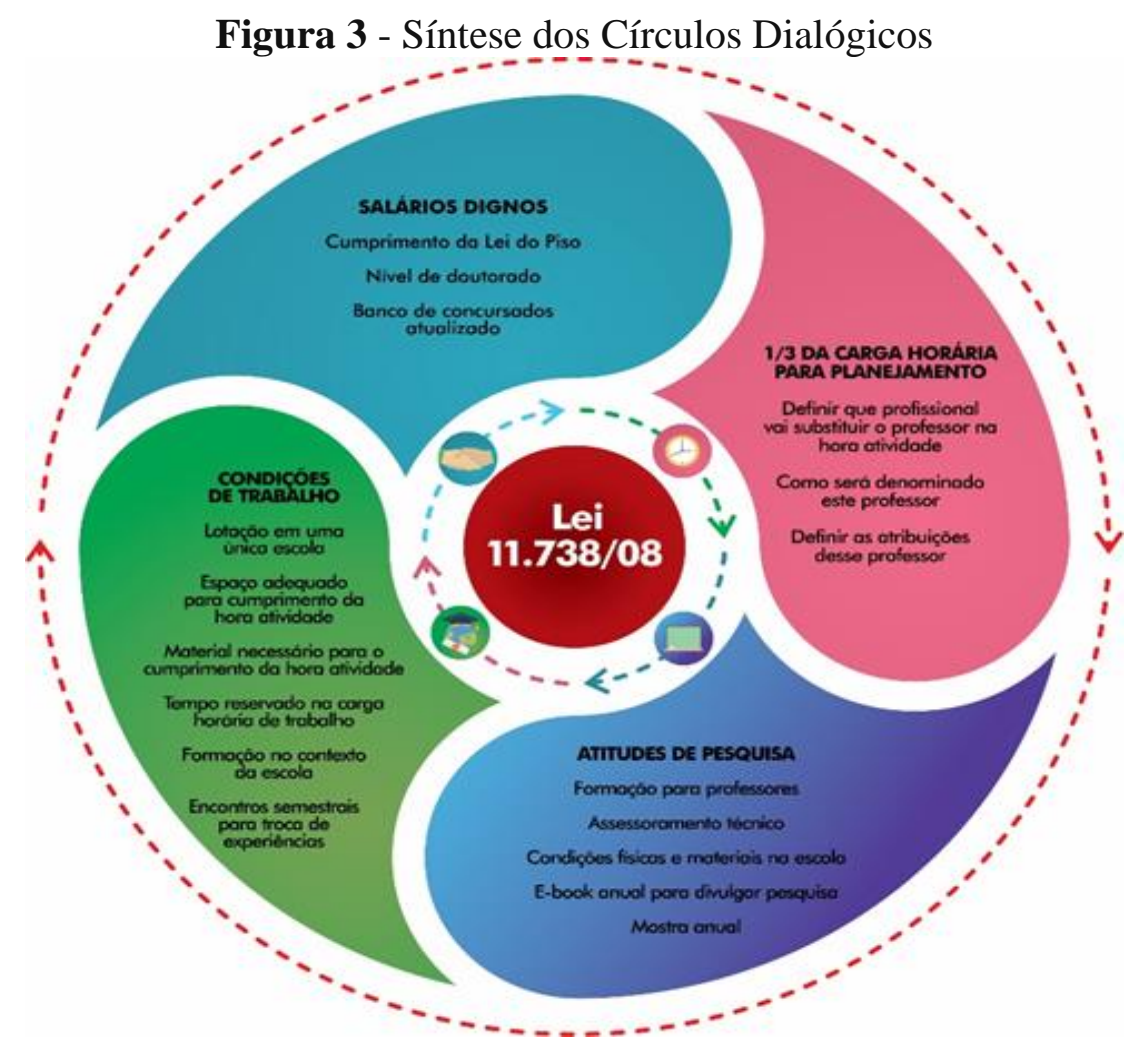

Fonte: as autoras (2019)

O resultado da pesquisa demonstrou que se faz imprescindível valorizar a carreira docente com salários dignos de acordo com a função social que o professor exerce enquanto trabalhador da educação, respeitando a Lei $n^{\circ} 11.738 / 08$, bem como sua formação com Plano de Carreira que reconheça o esforço em buscar aperfeiçoamento em cursos de Pós-Graduação acrescentando na matriz salarial o nível de doutorado, atualmente contempla até o nível de mestrado.

Também, garantir quadro de professores que seja capaz de assegurar o cumprimento do direito à hora atividade destinando $1 / 3$ da carga horária conforme a Lei ${ }^{\circ}$ 11.738/08 sem comprometer o direito do aluno à carga horária de estudos estabelecida pela legislação.

Outro ponto fundamental é oferecer condições de trabalho ao professor para executar seu ofício sem precisar dividir sua carga horária em muitas escolas, estrutura física e material ideal para realizar a hora atividade seja em funções de planejamento de atividades, avaliação 
ou reuniões pedagógicas de estudo e formação respeitando a autonomia pedagógica de cada unidade escolar na construção de seus projetos de formação permanente, partindo do princípio que cada escola é capaz de saber o que é fundamental no seu processo de formação com o objetivo de qualificar seus espaços/tempos em benefício de sua comunidade escolar considerando:

Importante destacar que o incentivo para atitudes de pesquisa sobre as práticas cotidianas do professor no sentido de proporcionar a reflexão na prática e sobre a prática e a divulgação das mesmas revelou-se como necessidade indispensável.

Do resultado das discussões realizadas no Círculos Dialógicos organizou-se um documento que será entregue na Secretaria de Município da Educação. Construído com professores da Rede Municipal de Santa Maria - RS que fazem parte da Coordenação do Sindicato dos Professores Municipais (SINPROSM), pressupondo a relevância do diálogo com o objetivo de refletir sobre os desafios encontrados a fim de promover a qualificação do espaço-tempo reservado no Plano de Carreira dos Professores Municipais de Santa Maria RS, Lei Municipal no 4.696/03, especificamente o artigo 22 que garante, no mínimo, 20\% da carga horária para estudos, planejamento e avaliação do trabalho didático, posteriormente referendado pela Lei $\mathrm{n}^{\circ}$ 11.738/08 (Lei do Piso Salarial Profissional Nacional) que assegura no $\operatorname{artigo} 2^{\circ}$, $\S 4^{\circ}$ que na composição da jornada de trabalho, observar-se-á o limite máximo de 2/3 (dois terços) da carga horária para o desempenho das atividades de interação com os educandos.

É nesta perspectiva que devemos considerar a importância da Lei do Piso Salarial Profissional Nacional, Lei $\mathrm{n}^{\mathrm{o}} 11.738 / 08$, tanto em termos salariais quanto em relação às condições de trabalho efetivadas na composição da jornada de trabalho que esta lei determina e que dá possibilidades de proporcionar a formação permanente de professores. Destacamos o Parecer 18/12 CNE/CEB que aborda a necessidade de garantir condições de trabalho para o professor como fator necessário para assegurar a qualidade do ensino com salários dignos e compatíveis com a importância de sua função social e sua formação.

\section{Considerações finais}

Se considerarmos que um dos grandes desafios da educação brasileira é alcançar a universalização do acesso, bem como garantir a permanência e a conclusão com sucesso dos estudantes na escola compreendendo a educação em sua especificidade, qual seja a de formar pessoas, o trabalho do professor precisa ser percebido, reconhecido como elemento 
importante no processo educativo. Seu trabalho é determinante para a qualidade da educação. Para corresponder à importância deste papel social, o trabalho do professor precisa ser valorizado enquanto categoria.

Nessa direção, o diálogo empreendido através da palavra pronunciada por meio dos Círculos Dialógicos procurou, por intermédio da emersão de temáticas sobre o direito garantido na legislação, desvelar as concepções dos professores a respeito do tempo garantido no Plano de Carreira do Magistério de Santa Maria, respaldado pela Lei do Piso como oportunidade de formação permanente de professores e buscar compreender como o Plano de Carreira dos professores municipais de Santa Maria - RS contribui para o desenvolvimento profissional no âmbito da formação permanente com vistas a qualificar a hora atividade e como o sindicato pode se constituir protagonista nesse processo.

Assim, a partir de concepções teóricas sobre desenvolvimento profissional e formação permanente, as políticas públicas para formação de professores e identificando a atribuição do sindicato no desenvolvimento profissional no âmbito da formação permanente com vistas a qualificar a hora atividade, foi possível através das vivências dos movimentos dos Círculos Dialógicos, resultou na construção de uma Proposta para qualificar o Plano de Carreira dos Professores Municipais de Santa Maria - RS, que será encaminhada para a Secretaria de Educação do Município com a pretensão de colaborar na construção de caminhos que conduzam a valorização da carreira docente enquanto perspectiva de considerar o espaço/tempo reservado no Plano de Carreira como alternativa de formação permanente de professores.

\section{REFERÊNCIAS}

ALMEIDA, Maria Isabel. Desenvolvimento profissional docente: uma atribuição que também é do sindicato Disponível em: http://23reuniao.anped.org.br/textos/0412t.PDF. Acesso em: 02 out. 2019.

BRASIL. Constituição da República Federativa do Brasil de 1988. Disponível em: http://www.planalto.gov.br/ccivil_03/constituicao/constituicaocompilado.htm. Acesso em: 17 out. 2019.

BRASIL. Lei no 11.738/08. Regulamenta a alínea "e" do inciso III do caput do art. 60 do Ato das Disposições Constitucionais Transitórias, para instituir o Piso Salarial Profissional Nacional para os Profissionais do Magistério Público da Educação Básica. Disponível em: http://www.planalto.gov.br/ccivil_03/_ato2007-2010/2008/lei/111738.htm. Acesso em: 15 out. 2019. 
BRASIL. Lei no 9.394/96. Estabelece as Diretrizes e Bases para a Educação Nacional. Disponível em: http://www.planalto.gov.br/ccivil_03/leis/L9394.htm. Acesso em: 15 out. 2019.

BRASIL. Lei no 11.494//07. Regulamenta o Fundo de Manutenção e Desenvolvimento da Educação Básica e Valorização dos Profissionais da Educação - FUNDEB. Disponível em: http://www.planalto.gov.br/ccivil_03/_ato2007-2010/2007/lei/111494.htm. Acesso em 12 out. 2019.

BRASIL. Lei no 13.005/14. Aprova o Plano Nacional de Educação - PNE e dá outras providências. Disponível em: http://www.planalto.gov.br/CCIVIL_03/_Ato20112014/2014/Lei/L13005.htm. Acesso em: 15 out. 2019.

BRASIL. Parecer CNE/CEB no 18/2012, que trata da implantação da Lei no ${ }^{\circ} 11.738 / 2008$, que institui o piso salarial profissional nacional para os profissionais do magistério público da Educação Básica. Disponível em:

http://portal.mec.gov.br/index.php?option=com_docman\&view=download\&alias $=11795$ pceb018-12\&category_slug=setembro-2012-pdf\&Itemid=30192. Acesso em: 15 out. 2019.

CHIZZOTTI, Antônio. Pesquisa qualitativa em ciências humanas e sociais.

Petropolis, RJ: Vozes, 2006.

FREIRE, Paulo. Pedagogia do oprimido. 17 ed. São Paulo: Paz e Terra. 1987.

GADAMER, Hans-Georg. Verdade e Método: traços fundamentais de uma hermenêutica filosófica. 3. ed. Petrópolis, RJ: Vozes, 1999.

GARCIA, Carlos Marcelo. Formação de professores para uma mudança educativa. Porto: Porto Editora. 1999.

HENZ, Celso Ilgo.; TONIOLO, Joze Medianeira dos Santos Andrade. Orgs. Dialogus: círculos dialógicos, humanização e auto(trans)formação de professores. São Leopoldo: Oikos. 2015.

HENZ, Celso Ilgo; FREITAS, Larissa Martins; SILVEIRA, Melissa Noal da. Círculos dialógicos investigativos-formativos: uma metodologia de pesquisa inspirada nos círculos de cultura freireanos. Perspectiva - Revista do Centro de Ciências da Educação,

Florianópolis, v. 36, n. 3, p. 835-850, jul./set., 2018. Disponível em:

https://periodicos.ufsc.br/index.php/perspectiva/article/view/2175795X.2018v36n3p835/pdf_ 1. Acesso em: 16 out. 2019

IBIAPINA, Ivana Maria Lopes de Melo. Pesquisa colaborativa: investigação, formação e produção de conhecimento. Brasília: Liber livro. 2008.

IMBERNÓN, Francisco. Formação docente e profissional: formar-se para a mudança e a incerteza. 9 ed. São Paulo: Cortez. 2011.

NÓVOA, António. Formação de professores e profissão docente. In: NÓVOA, António. Os professores e sua formação. 2 ed. Lisboa: publicações dom quixote instituto de inovação educacional, Nova Enciclopédia, 1995. 
NÓVOA, António. Professores: imagens do futuro presente. Portugal: Fora de Coleção, 2009.

ROZEK, Marlene. As contribuições de Hans-Georg Gadamer para a formação de professores. In: Anais [...]SEMINÁRIO ANPED SUL. 9 ed, Caxias do Sul, 2012. Caxias do Sul: ANPEd, 2012. Disponível em: \&lt;http://www.ucs.br/etc/conferencias/index.php/ anpedsul/9anpedsul/paper/viewFile/851/512\&gt. Acesso em: 5 jul. 2019.

SANTA MARIA. Lei Municipal No 4.696/03. Estabelece o Plano de Carreira dos Professores Municipais. Disponível em:

http://www.santamaria.rs.gov.br/docs/Pub_23080226-66.pdf. Acesso em: 25 jun. 2018.

\section{Como citar esse artigo:}

NAJAR, Martha Izabel Pauler; LUNARDI, Elisiane Machado. Desenvolvimento profissional docente na perspectiva da participação sindical: diálogos propositivos para qualificação do plano de carreira dos professores municipais de Santa Maria - RS. Revista Ibero-Americana de Estudos em Educação, Araraquara, v. 15, n. 1, p. 189-205, jan./mar. 2020. e-ISSN: 19825587. DOI: https://doi.org/10.21723/riaee.v15i1.13114

Submetido em: 13/06/2019

Revisões requeridas: 10/08/2019

Aprovado em: 20/09/2019

Publicado em: 02/01/2020 